\title{
Application and Robust H??control of PDC fuzzy Controller for Nonlinear Systems with External Disturbance
}

\author{
Wei-Ling Chiang \\ Professor, Department of Civil Engineering, National Central University, Chung-Li, Taiwan, R.O.C. \\ Treng-Wu Chen \\ Ph.D. Student, Department of Civil Engineering, National Central University, Chung-Li, Taiwan, R.O.C. \\ Ming-Yi Liu \\ Ph.D. from Department of Civil Engineering, National Central University, Chung-Li, Taiwan, R.O.C. \\ Chun-Jung Hsu \\ Ph.D. Student, Department of Civil Engineering, National Central University, Chung-Li, Taiwan, R.O.C.
}

Follow this and additional works at: https://jmstt.ntou.edu.tw/journal

Part of the Civil and Environmental Engineering Commons

\section{Recommended Citation}

Chiang, Wei-Ling; Chen, Treng-Wu; Liu, Ming-Yi; and Hsu, Chun-Jung (2001) "Application and Robust H??control of PDC fuzzy Controller for Nonlinear Systems with External Disturbance," Journal of Marine Science and Technology. Vol. 9: Iss. 2, Article 3.

DOI: $10.51400 / 2709-6998.2438$

Available at: https://jmstt.ntou.edu.tw/journal/vol9/iss2/3

This Research Article is brought to you for free and open access by Journal of Marine Science and Technology. It has been accepted for inclusion in Journal of Marine Science and Technology by an authorized editor of Journal of Marine Science and Technology. 


\title{
APPLICATION AND ROBUST $H^{\infty}$ CONTROL OF PDC FUZZY CONTROLLER FOR NONLINEAR SYSTEMS WITH EXTERNAL DISTURBANCE
}

\author{
Wei-Ling Chiang, ${ }^{*}$ Treng-Wu Chen, ${ }^{* *}$ Ming-Yi Liu*** and Chun-Jung Hsu**
}

Keywords: resonance, chaos, fuzzy control, T-S fuzzy models.

\begin{abstract}
In terms of Lyapunov's direct method, a stability criterion is derived to guarantee the stability of the system especially for the resonant and chaotic systems. The common P matrix of the criterion is obtained by using linear matrix inequality (LMI) optimization algorithms to solve the robust fuzzy control problem. Based on the control scheme and this criterion, a fuzzy controller is then designed via the technique of parallel distributed compensation (PDC) to stabilize the nonlinear system. Finally, the proposed controller design method is demonstrated through numerical simulations on the chaotic and resonant systems.
\end{abstract}

\section{INTRODUCTION}

Many control methods have been proposed to overcome the difficulty of dealing with nonlinear systems with the phenomenon of bifurcation, chaos, limit cycle and so on [1]. Since the design of control strategy of nonlinear systems is a difficult process and the plants are in general nonlinear in practical sense. Due to the complexity of designing a general control scheme for a nonlinear system, we proposed here a simplified model for the purpose. In the past few years, fuzzy-rule-based modeling has become an active research field because of its unique merits in solving complex nonlinear system identification and control problems. In attempt to attain more flexibility and more effective capability of handling and processing uncertainties in complicated and ill-defined systems, Zadeh [2] proposed a linguistic approach as the model of human thinking, which introduced the fuzziness into systems theory [3]. Unlike

Paper Received May 1, 2001. Author for Correspondence: W. L. Chiang. *Professor, Department of Civil Engineering, National Central University, Chung-Li, Taiwan, R.O.C.

**Ph.D. Student, Department of Civil Engineering, National Central University, Chung-Li, Taiwan, R.O.C.

***Ph.D. from Department of Civil Engineering, National Central University, Chung-Li, Taiwan, R.O.C. traditional modeling, fuzzy rule-based modeling is essentially a multimodel approach in which individual rules are combined to describe the global behavior of the system [4].

Fuzzy control has attracted a great deal of attention from both the academic and industrial communities in the past few years, and there have been many successful applications. In spite of the success, there are still many basic issues that remain to be further addressed. Stability analysis and systematic design are certainly among the most important issues for fuzzy control systems. During the last decade, fuzzy control has been successfully applied to the control design of nonlinear systems [5-7]. However, as far as we know, the stabilization problem of fuzzy resonant and chaotic systems remains unresolved.

Nevertheless, we often encounter the problems of resonant or chaotic systems in civil engineering field. The phenomenon of resonance occurs when the frequency of structure is the same as the external force. The magnitude of dynamic magnification factor $D_{\max }$ influences the degree of failure of the structure and we know the phenomenon will do a big damage to the structure [8]. Besides to predict the behavior of chaotic system is hard due to its unpredictability and irregularity [9]. In many cases, the reason why the chaos should be purposed controlled or avoided is that chaos could lead systems to undesirable performance-degraded situations. Broadly speaking, the objective of this paper is to derive a stability criterion for fuzzy model-based controller to guarantee the uniformly ultimately bounded (UUB) stable of nonlinear systems with chaotic and resonant characteristics.

This paper is organized as follows. First, the T-S fuzzy model is briefly reviewed and the system description is presented. Then, based on Lyapunov's approach, a stability criterion is derived to guarantee the stability of the system. Next, a fuzzy controller via the technique of PDC is proposed to stabilize the fuzzy system. Finally, a numerical example with simulations is given to illustrate the results, and the conclusions are drawn. 


\section{SYSTEM DESCRIPTION}

Consider a nonlinear system $N$ described as follows:

$$
\dot{x}(t)=f(x(t), u(t))+\phi(\mathrm{t})
$$

where $f$ is a nonlinear vector-valued function, $x(t)$ represents time, $x(t)$ is the state vector, $\dot{x}(t)$ is derivative of $x(t), u(t)$ is the input vector and $\phi(t)$ denotes the external disturbance.

Definition 1 [1]: The solution of a dynamic system are said to be uniformly ultimately bounded (UUB) if there exist positive constants $\beta$ and $\kappa$, for every $\delta \in(0, \kappa)$ there is a positive constant $T=T(\delta)$, such that

$$
\left\|x\left(t_{0}\right)\right\|<\delta \Rightarrow\|x(t)\| \leq \beta, \forall t \geq t_{0}+T .
$$

Assumption 1: $f(0)=0$ so the origin is an equilibrium point of the system (1).

Local linear input/output relations of nonlinear systems using fuzzy dynamical models have been developed primarily from the pioneering work of Takagi and Sugeno [10]. Accordingly, the system $\boldsymbol{N}$ is approximated by a T-S fuzzy model of which is described by fuzzy IF-THEN rules. The main feature of T-S fuzzy models is to express each rule by a linear state equation, and the ith rule of this fuzzy model is of the following form:

Rule $i$ : IF $x_{1}(t)$ is $M_{i 1}$ and $\ldots$ and $x_{g}(t)$ is $M_{i g}$

$$
\text { THEN } \dot{x}(t)=A_{i} x(t)+B_{i} u(t)+\phi(t)
$$

where $x^{T}(t)=\left[x_{1}(t), x_{2}(t), \ldots, x_{g}(t)\right] \in R^{1 \times g}$ denotes the state vector,

$u^{T}(t)=\left[u_{1}(t), u_{2}(t), \ldots, u_{m}(t)\right] \in R^{1 \times m}$ denotes the control input,

$\phi(t)=\left[\phi_{1}(t), \phi_{2}(t), \ldots, \phi_{j}(t)\right] \in R^{1 \times j}$ denotes the unknown disturbances with a known upper bound $\phi_{u p}(t)$ $\geq\|\phi(t)\| \cdot i=1,2, \ldots, r$ and $r$ is the number of IF-THEN rules; $A_{i}$ and $B_{i}$ are constant matrices with appropriate

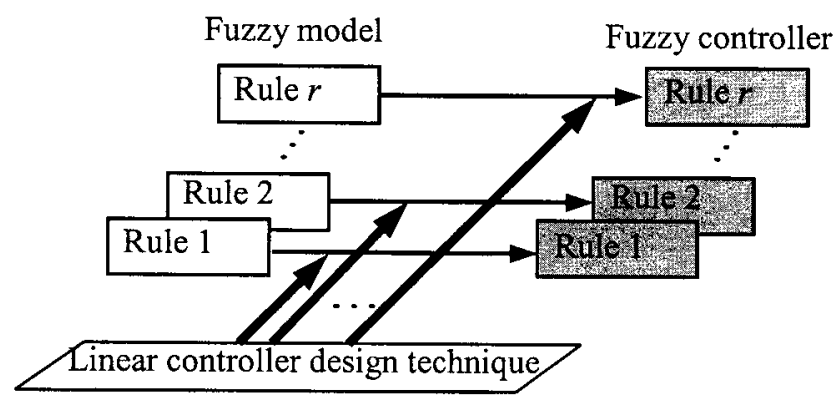

Fig. 1. Parallel-distributed-compensation (PDC) design. dimensions; $M_{i p}(p=1,2, \ldots, g)$ are the fuzzy sets, and $x_{1}(t) \sim x_{g}(t)$ are the premise variables. The final state of this fuzzy dynamic model is inferred as follows:

$$
\begin{aligned}
\dot{x}(t) & =\frac{\sum_{i=1}^{r} w_{i}(t)\left[A_{i} x(t)+B_{i} u(t)+\phi(t)\right]}{\sum_{i=1}^{r} w_{i}(t)} \\
& =\sum_{i=1}^{r} h_{i}(t)\left(A_{i} x(t)+B_{i} u(t)\right)+\phi(t)
\end{aligned}
$$

with

$$
w_{i}(t)=\prod_{p=1}^{g} M_{i p}\left(x_{p}(t)\right), h_{i}(t)=\frac{w_{i}(t)}{\sum_{i=1}^{r} w_{i}(t)}
$$

in which $M_{i p}\left(x_{p}(t)\right)$ is the grade of membership of $x_{p}(t)$ in $M_{i p}$. In this paper, it is assumed that $w_{i}(\mathrm{t}) \geq 0, i=1$, $2, \ldots, r$; and $\sum_{i=1}^{r} w_{i}(t)>0$ for all $t$. Therefore, $h_{i}(t) \geq 0$ and $\sum_{i=1}^{r} h_{i}(t)=1$ for all $t$.

In the next section, the concept of PDC scheme is utilized to design the fuzzy controller.

\section{PARALLEL DISTRIBUTED COMPENSATION}

The concept of PDC scheme illustrated in Fig. 1 is that each control rule is distributively designed for the corresponding rule of a T-S fuzzy model. The fuzzy controller shares the same fuzzy sets with the fuzzy model in the premise parts [6]. Since each rule of the fuzzy model is described by a linear state equation, linear control theory can be used to design the consequent parts of a fuzzy controller. The resulting overall fuzzy controller, nonlinear in general, is achieved by fuzzy blending of each individual linear controller.

Hence, the $j$ th fuzzy controller can be described as follows:

Rule $i$ : IF $x_{1}(t)$ is $M_{i 1}$ and $\ldots$ and $x_{g}(t)$ is $M_{i g}$

$$
\text { THEN } u(t)=-K_{i} x(t),
$$

where $K_{i}$ is a constant controller gain matrix and $i=1$, $2, \ldots, r$. The final output of this model-based fuzzy controller is

$$
u(t)=-\frac{\sum_{i=1}^{r} w_{i}(t) K_{i} x(t)}{\sum_{i=1}^{r} w_{i}(t)}=-\sum_{i=1}^{r} h_{i}(t) K_{i} x(t)
$$

Substituting Eq. (6) into Eq. (3) yields the closedloop fuzzy system $\overline{\boldsymbol{F}}$ as follows:

$$
\dot{x}(t)=\sum_{i=1}^{r} \sum_{l=1}^{r} h_{i}(t) h_{l}(t)\left[\left(A_{i}-B_{i} k_{l}\right) x(t)\right]+\phi(t)
$$




\section{$H^{\infty}$ CONTROL DESIGN VIA FUZZY CONTROL}

The purpose of this paper is two-fold: to stabilize the closed-loop nonlinear system and to attenuate the influence of the external disturbance $\phi(t)$ on the state variable $\boldsymbol{x}(t)[11,12]$. The influence of $\phi(t)$ will worsen the performance of fuzzy control system. So, to guarantee the control performance by eliminating the influence of $\phi(t)$ is a significant problem in the control system. In this work, not only the stability of fuzzy control system is advised but also the $H^{\infty}$ control performance is satisfied as follows:

$$
\int_{0}^{t_{f}} x(t)^{T} Q x(t) d t \leq \eta^{2} \int_{0}^{t_{f}} \phi(t)^{T} \phi(t) d t
$$

where $t_{f}$ denotes the terminal time of the control, $\eta$ is a prescribed value which denotes the effect of $\phi(t)$ on $x(t)$, and $Q$ is a positive definite weighting matrix. The physical meaning of (8) is that the effect of $\phi(t)$ on $x(t)$ must be attenuated below a desired level $\eta$ from the viewpoint of energy.

If the initial condition is also considered, the inequality (8) can be modified as

$$
\int_{0}^{t_{f}} x(t)^{T} Q x(t) d t \leq x(0)^{T} P x(0)+\eta^{2} \int_{0}^{t_{f}} \phi(t)^{T} \phi(t) d t
$$

where $P$ are some positive definite matrices.

Herein, a stability criterion is given below to guarantee the stability and control performance of the closedloop fuzzy system (7). Prior to examination of stability of $\boldsymbol{F}$, an useful concept is given below.

Lemma 1 [13]: For real matrices A and B with appropriate dimensions, we have

$$
A^{T} B+B^{T} A \leq \sigma A^{T} A+\sigma^{-1} B^{T} B \text { where } \sigma \text { is a positive }
$$
constant.

Theorem 1: The closed-loop fuzzy system $\overline{\boldsymbol{F}}$ is stable, if there exist symmetric positive definite matrix $P$ and a positive constant $\gamma$ and the feedback gains $K_{i}$ shown in Eq. (6) are chosen to satisfy the following conditions:

$$
\begin{aligned}
& {\left[\left(A_{i}-B_{i} K_{i}\right)^{T} P+P\left(\mathrm{~A}_{i}-B_{i} K_{i}\right)\right]+\gamma^{-1} P^{2}+Q<0} \\
& \text { for } i=1,2, \ldots, r, \\
& {\left[H_{i l}^{T} P+P H_{i l}\right]+\gamma^{-1} P^{2}+Q<0} \\
& \text { for } i \leq l \leq r,
\end{aligned}
$$

with $H_{i 1}=\frac{\left(A_{i}-B_{i} K_{l}\right)+\left(A_{l}-B_{l} K_{i}\right)}{2}, P=P^{T}>0$.

The proof is in the appendix.

\section{ALGORITHM}

Based on the above analysis, the complete design procedure can be summarized in the following algorithm. Problem: For a given nonlinear system $\boldsymbol{N}$, how do we design a model-based fuzzy controller to stabilize the nonlinear system $\boldsymbol{N}$ ?

The problem described above can be solved by the following steps.

Step 1: Select fuzzy plant rules and membership functions for each nonlinear system to establish its T-S fuzzy model.

Step 2: Design a model-based fuzzy controller via the concept of PDC scheme.

Step 3: If there exist a positive definite matrix $P$ to satisfy the stability condition of Theorem 1 , the fuzzy system $\boldsymbol{F}$ can be stabilized by finding a appropriate model-based fuzzy controller in Step 2.

\section{EXAMPLES}

We will design a T-S fuzzy controller for a simple nonlinear mass-spring-damper mechanical system. Resonant system is considered when the frequency of the external force is the same as the system and duffing equation is considered for a large displacement [1]. The objective of this section is to design a fuzzy controller such that the nonlinear systems $\boldsymbol{N}$ described as follows are stable.

\section{system 1 (resonant system):}

$\left\{\begin{array}{l}\dot{x}_{1}(t)=2.5 x_{2}(t) \\ \dot{x}_{2}(t)=-\omega^{2} x_{1}(t)-0.01 x_{1}^{2}-2 \xi \omega x_{2}(t)+\sin (1.581 t)+f_{1} u(t)\end{array}\right.$

\section{system 2 (chaotic system):}

$$
\left\{\begin{array}{l}
\dot{x}_{1}(t)=2.5 x_{2}(t) \\
\dot{x}_{2}(t)=-\left(\frac{1}{2.5} x_{1}(t)\right)^{3}-\frac{1}{2.5} x_{1}(t)-0.1 x_{2}(t)+25 \cos (1.29 t)+f_{2} u(t)
\end{array}\right.
$$

where $\omega$ denotes the frequency of the system, $\xi$ denotes the damping ratio, $u(t)$ denotes the control force, $f_{1}$ and $f_{2}$ denote the constant coefficient of control forces.

In resonant system [8], the possible response of the system with no control force are (a) $\xi=0$, (b) $0<\xi<1$, (c) $\xi>1$ simulated in Fig. 2. However, due to external force the state of the resonant system would oscillate for a long time. In the same way, there exist many sets of harmonic solutions in chaotic system. When a given initial condition produces a chaos solution, then a arbi- 


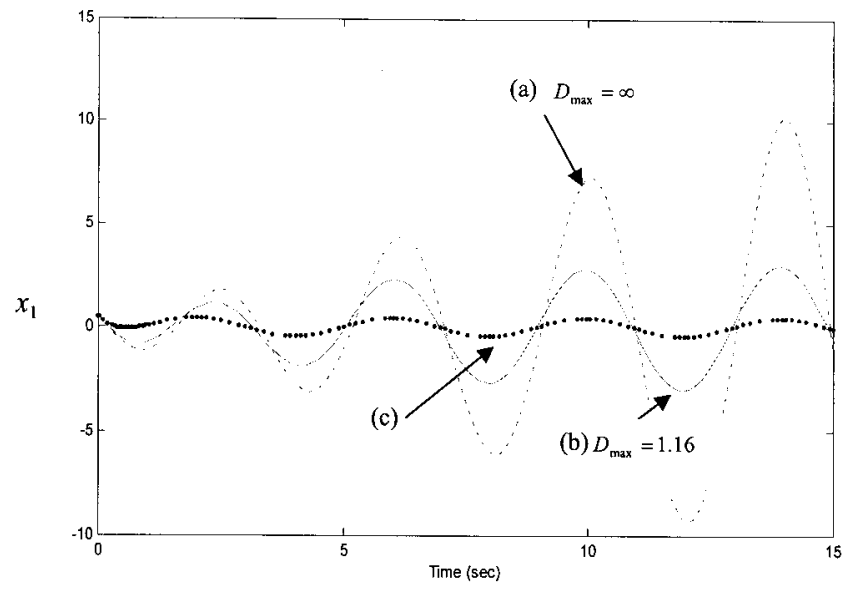

Fig. 2. Response (a) $\xi=0,(\mathrm{~b}) 0<\xi<1,(\mathrm{c}) \xi>1$ of the resonant system with no control force system 1 .

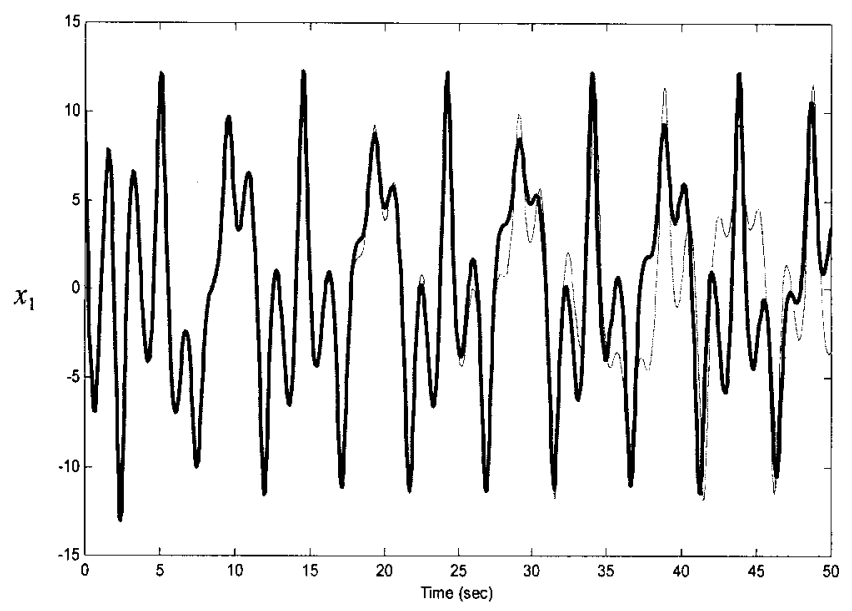

Fig. 3. Chaotic behavior of a nonlinear system with no control force.

trary initial condition will make the state of nonlinear system chaotic. In chaos, the system output is extremely sensitive to initial conditions. Fig. 3 shows the responses of the system with no control force corresponding to two almost identical initial conditions, namely $x_{1}(0)=10, x_{2}(0)=-15$ (thin line) and $x_{1}(0)=$ $10.01, x_{2}(0)=-15.01$ (thick line). Fig. 4 shows the phase-plane trajectory of the same simulation result with $x_{1}(0)=10, x_{2}(0)=-15$.

Nevertheless, how do we design fuzzy controllers to stabilize two cases of above systems $N$ with $\omega=1, \xi$ $=0, f_{1}=f_{2}=4.5$ ?

Solution: We can solve this problem according to the following steps.

Step 1: Establish a T-S fuzzy model for each nonlinear system. To minimize the design effort and complexity, we try to use as few rules as possible.

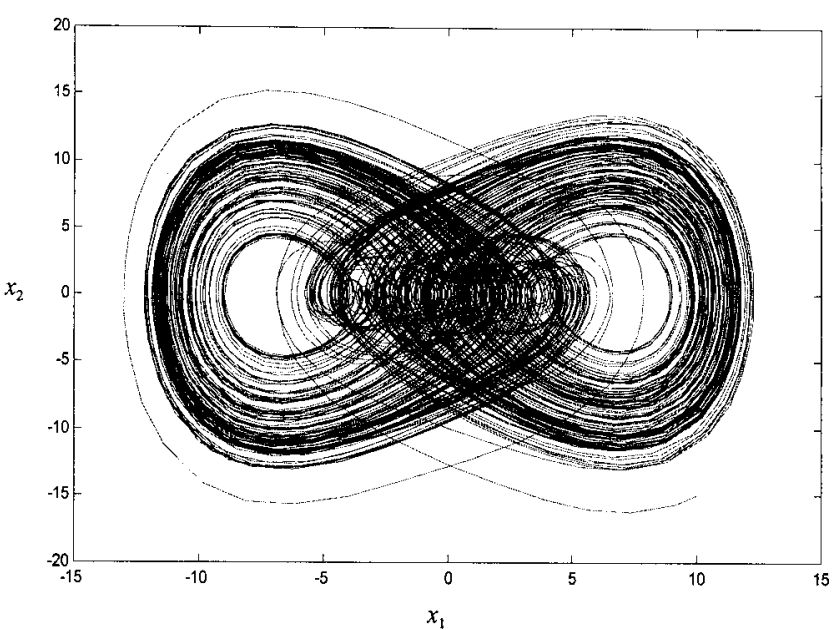

Fig. 4. Phase-plane trajectory of the chaotic system.

Hence, the systems (11-12) are approximated with the following fuzzy models:

T-S fuzzy model of system 1 and system 2:

Rule 1: IF $x_{1}(t)$ is $M_{11}$

THEN $\dot{x}(t)=A_{1} x(t)+B_{1} u(t)$

Rule 2: IF $x_{1}(t)$ is $M_{21}$

THEN $\dot{x}(t)=A_{2} x(t)+B_{2} u(t)$.

System 1:

$$
\begin{aligned}
& x^{T}(t)=\left[\begin{array}{ll}
x_{1}(t) & x_{2}(t)
\end{array}\right], A_{1}=\left[\begin{array}{cc}
0 & 2.5 \\
-1 & 0
\end{array}\right], \\
& A_{2}=\left[\begin{array}{cc}
0 & 2.5 \\
-1.01 & 0
\end{array}\right], \quad B_{1}=\left[\begin{array}{c}
0 \\
4.5
\end{array}\right], \quad B_{2}=\left[\begin{array}{c}
0 \\
4.5
\end{array}\right]
\end{aligned}
$$

and the membership functions for Rule 1 and Rule 2 are

$$
\begin{array}{ll} 
\begin{cases}M_{11}\left(x_{1}(t)\right)=\frac{1}{2 \pi} x_{1}(t)+1 & \text { when }-2 \pi \leq x_{1}(t) \leq 0 \\
M_{11}\left(x_{1}(t)\right)=-\frac{1}{2 \pi} x_{1}(t)+1 & \text { when } 0<x_{1}(t) \leq 2 \pi \\
M_{11}\left(x_{1}(t)\right)=0 & \text { otherwise, }\end{cases} \\
M_{21}\left(x_{1}(t)\right)=1-M_{11}\left(x_{1}(t)\right) . &
\end{array}
$$

\section{System 2:}

$$
\begin{aligned}
& x^{T}(t)=\left[\begin{array}{ll}
x_{1}(t) & x_{2}(t)
\end{array}\right], A_{1}=\left[\begin{array}{cc}
0 & 2.5 \\
-0.4 & -0.1
\end{array}\right], \\
& A_{2}=\left[\begin{array}{cc}
0 & 2.5 \\
-0.41 & -0.1
\end{array}\right], \quad B_{1}=\left[\begin{array}{c}
0 \\
4.5
\end{array}\right], \quad B_{2}=\left[\begin{array}{c}
0 \\
4.5
\end{array}\right]
\end{aligned}
$$

and membership functions for Rule 1 and Rule 2 are the 
same as the system 1.

Step 2: In order to stabilize the fuzzy system $\boldsymbol{F}$, two model-based fuzzy controllers designed via the concept of PDC scheme are displaying as follows.

Fuzzy controllers of system 1 and system 2:

Rule 1: IF $x_{1}(\mathrm{t})$ is $M_{11}$ THEN u(t) $=-K_{1} x(t)$,

Rule 2: IF $x_{1}(\mathrm{t})$ is $M_{21}$ THEN u(t) $=-K_{2} x(t)$,

Step 3: For the purpose of fulfilling the stability conditions of Theorem 1 , the matrices $Q$ are chosen to be positive definite. Hence, based on Eqs. (13-15), we can obtain the following positive definite matrices $P$ and $K_{i}$ via LMI optimization algorithms with $\gamma=0.22$ in system 1 and $\gamma=0.31$ in system 2 :

$$
\begin{aligned}
\text { system 1: } P_{1} & =\left[\begin{array}{cc}
5.6115 & 2.5 \\
2.5 & 1.5405
\end{array}\right], \\
\text { system 2: } P_{2} & =\left[\begin{array}{ll}
5.820 & 2.313 \\
2.313 & 1.363
\end{array}\right], \\
\text { system 1: } K_{1} & =\left[\begin{array}{ll}
33.378 & 19.889
\end{array}\right] \text { and } \\
K_{2} & =\left[\begin{array}{ll}
17.776 & 11.000
\end{array}\right], \\
\text { system 2: } K_{1} & =\left[\begin{array}{ll}
27.822 & 16.533
\end{array}\right] \text { and } \\
K_{2} & =\left[\begin{array}{ll}
11.820 & 7.644
\end{array}\right],
\end{aligned}
$$

The inequality (10) is satisfied. Therefore, based on conditions of Theorem 1, the T-S fuzzy controllers (15) can stabilize two cases of fuzzy systems $\boldsymbol{F}$. To assess the effectiveness of the fuzzy controllers, we apply the same T-S fuzzy controllers to nonlinear systems $N$ described in Eqs. (11-12). Simulation results of each system are illustrated in Figs. 5-6 and control forces are showed in Figs. 7-8. In Figs. 5-6, nonlinear resonant and chaotic systems would be stabilized via the robust criterion in this paper.

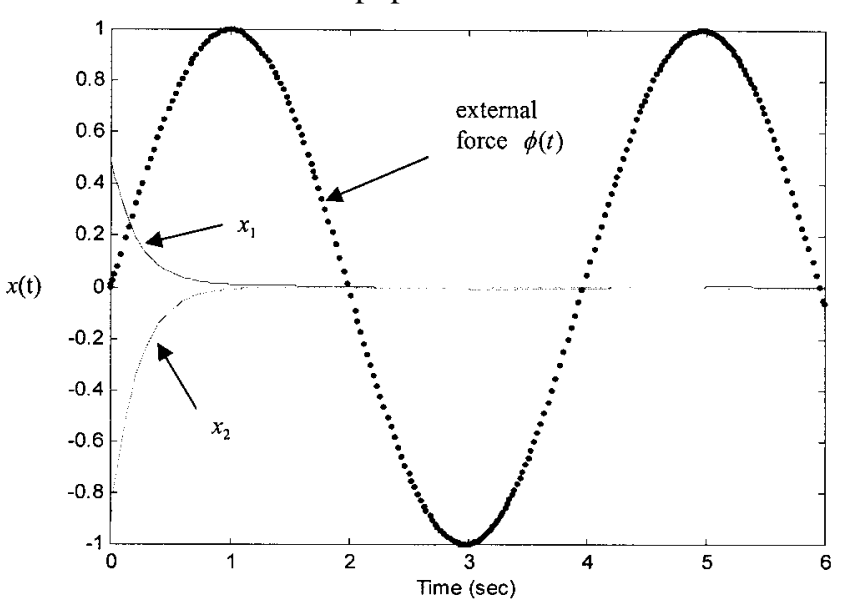

Fig. 5. The state response of system 1.

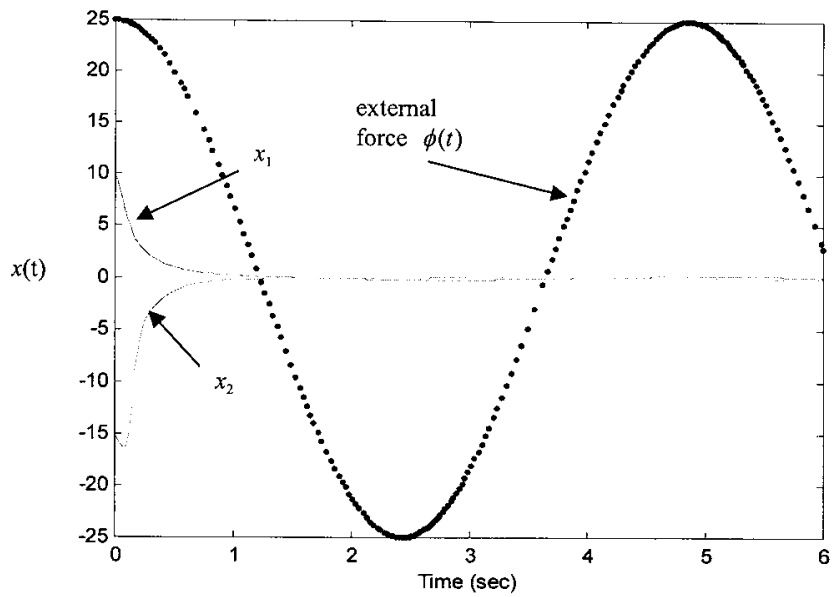

Fig. 6. The state response of system 2 .

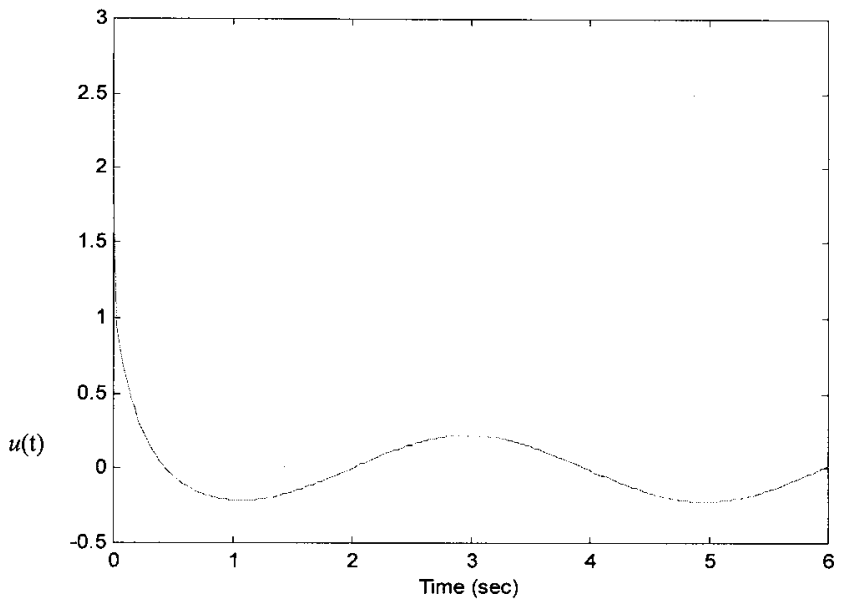

Fig. 7. The control force of system 1.

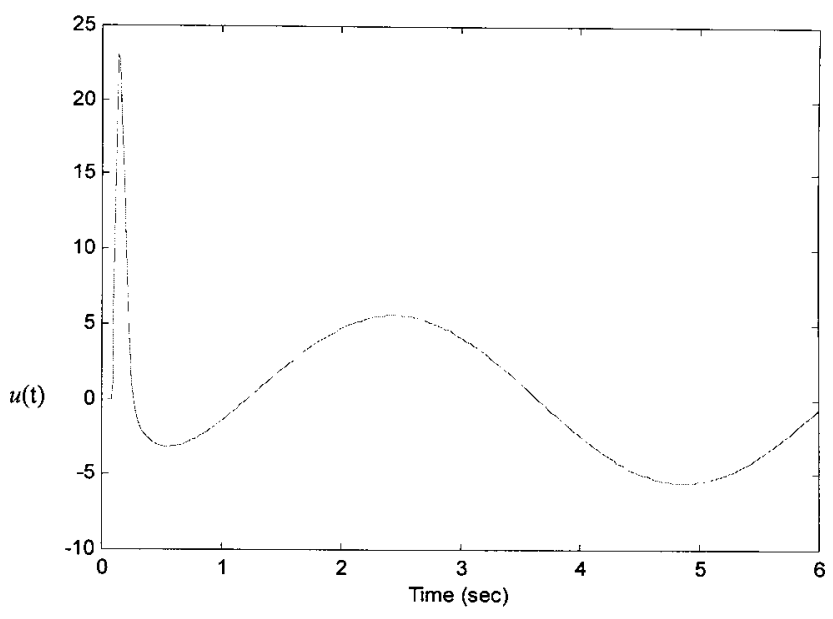

Fig. 8. The control force of system 2 . 


\section{CONCLUSIONS}

In order to ensure the stability of nonlinear systems, a stability criterion is derived from Lyapunov's direct method. According to this criterion and the control scheme, a model-based fuzzy controller is to stabilize the nonlinear system. So, the proposed fuzzy linear control can be applied to any robust control design of nonlinear system. Finally, an example is given to illustrate the concepts discussed in the paper.

\section{APPENDIX: PROOF OF THEOREM 1}

Let the Lyapunov function for the nonlinear system $\bar{N}$ be defined as

$$
V=x^{T}(t) P x(t) .
$$

We then evaluate the time derivative of $V$ on the trajectories of Eq. (7) to get

$$
\begin{aligned}
\dot{V} & =\left[\dot{x}^{T}(t) P x(t)+x^{T}(t) P \dot{x}(t)\right] \\
& =\left\{\sum_{i=1}^{r} \sum_{l=1}^{r} h_{i}(t) h_{l}(t)\left[\left(A_{i}-B_{i} K_{l}\right) x(t)\right]+\phi(t)\right\}^{T} P x(t) \\
& +x^{T}(t) P\left\{\sum_{i=1}^{r} \sum_{l=1}^{r} h_{i}(t) h_{l}(t)\left[\left(A_{i}-B_{i} K_{l}\right) x(t)\right]+\phi(t)\right\} \\
& =\sum_{i=1}^{r} \sum_{l=1}^{r} h_{i}(t) h_{l}(t) x^{T}(t)\left[\left(A_{i}-B_{i} K_{l}\right)^{T} P\right. \\
& \left.+P\left(A_{i}-B_{i} K_{l}\right)\right] x(t)+\left[\phi^{T}(t) P x(t)+x^{T}(t) P \phi(t)\right] \\
& \leq \sum_{i=1}^{r} \sum_{l=1}^{r} h_{i}(t) h_{l}(t) x^{T}(t)\left[\left(A_{i}-B_{i} K_{l}\right)^{T} P\right. \\
& \left.+P\left(A_{i}-B_{i} K_{l}\right)\right] x(t)+\gamma\left[\phi^{T}(t) \phi(t)\right]+\gamma^{-1}\left[x^{T}(t) P^{2} x(t)\right] \\
& \left(\text { from Lemma 1) }=D_{1}+D_{2}+\gamma \phi^{T}(t) \phi(t), \quad\right. \text { (A2) }
\end{aligned}
$$

where

$$
\begin{aligned}
D_{1} & \equiv \sum_{i=1}^{r} \sum_{l=1}^{r} h_{i}(t) h_{l}(t) x^{T}(t)\left[\left(A_{i}-B_{i} K_{l}\right)^{T} P\right. \\
& +P\left(A_{i}-B_{i} K_{l}\right) x(t) \\
& =\sum_{i=l=1}^{r} h_{i}^{2}(t) x^{T}(t)\left[\left(A_{i}-B_{i} K_{l}\right)^{T} P\right. \\
& \left.+P\left(A_{i}-B_{i} K_{l}\right)\right] x(t) \\
& +2 \sum_{i<1}^{r} h_{i}(t) h_{l}(t) x^{T}(t)\left[H_{i l}^{T} P+P H_{i l}\right] x(t), \\
D_{2} & \equiv \gamma^{-1}\left[x^{T}(t) P^{2} x(t)\right] \\
& =\sum_{i=1}^{r} \sum_{l=1}^{r} h_{i}(t) h_{l}(t) \gamma^{-1}\left[x^{T}(t) P^{2} x(t)\right]
\end{aligned}
$$

$$
\begin{aligned}
& \left.=\sum_{i=l=1}^{r} h_{i}^{2}(t) x^{T}(t)\left[\gamma^{-1} P^{2}\right] x(t)\right] \\
& \left.+2 \sum_{i<1}^{r} h_{i}(t) h_{l}(t) x^{T}(t)\left[\gamma^{-1} P^{2}\right] x(t)\right]
\end{aligned}
$$

Substituting Eqs. (A3-A4) into Eq. (A2) yields

$$
\begin{aligned}
\dot{V} & \leq \sum_{i=l=1}^{r} h_{i}^{2}(t) x^{T}(t)\left\{\left[\left(A_{i}-B_{i} K_{l}\right)^{T} P+P\left(A_{i}-B_{i} K_{l}\right)\right]\right. \\
& \left.\left.+\gamma^{-1} P^{2}\right\} x(t)\right)+2 \sum_{i<1}^{r} h_{i}(t) h_{l}(t) x^{T}(t)\left\{\left[H_{i l}^{T} P+P H_{i l}\right]\right. \\
& \left.+\gamma^{-1} P^{2}\right\} x(t)+\gamma \phi^{T}(t) \phi(t) .
\end{aligned}
$$

Based on Eqs. (10a-10b) and (A5),

$$
\begin{aligned}
\dot{V} & \leq \sum_{i=l=1}^{r} h_{i}^{2}(t) x^{T}(t)\{-Q\} x(t) \\
& +2 \sum_{i<1}^{r} h_{i}(t) h_{l}(t) x^{T}(t)\{-Q\} x(t)+\gamma \phi^{T}(t) \phi(t) \\
& =-x^{T}(t) Q x(t)+\gamma \phi^{T}(t) \phi(t)
\end{aligned}
$$

According to Definition 1, the demonstrates that the trajectories of the closed-loop system (7) are UUB. Integrating (A6) from $t=0$ to $t=t_{f}$ yields

$$
\begin{aligned}
& V\left(t_{f}\right)-V(0) \leq-\int_{0}^{t_{f}} x(t)^{T} Q x(t) d t \\
& +\gamma \int_{0}^{t_{f}} \phi(t)^{T} \phi(t) d t .
\end{aligned}
$$

From (A1), we get

$$
\int_{0}^{t_{f}} x(t)^{T} Q x(t) d t \leq x^{T}(0) P x(0)+\gamma \int_{0}^{t_{f}} \phi(t)^{T} \phi(t) d t
$$

That is Eq. (9) and the $H^{\infty}$ control performance is achieved with a prescribed $\gamma=\eta^{2}$.

\section{REFERENCES}

1. Khalil H. K., Nonlinear Systems. London, U.K.: Macmilllan, 1992.

2. Zadeh L. A., "Outline of a new approach to the analysis of complex systems and decision processes," IEEE Trans. Syst., Man, Cybern., Vol. 3, pp. 28-44 (1973).

3. Mohammad R. E., Turksen I. B. and Andrew A. G., "Development of a systematic methodology of fuzzy logic modeling," IEEE Trans. Fuzzy Syst., Vol. 6, pp. 346-360 (1998).

4. Yen J. and Wang L., "Simplifying fuzzy rule-based models using orthogonal transformation methods," IEEE Trans. Syst., Man, Cybern., part B, Vol. 29, pp. 13-24 (1999).

5. Wang H. O., Tanaka K. and Griffin M. F., "An approach to fuzzy control of nonlinear systems: stability and design issues," IEEE Trans. Fuzzy Syst., Vol. 4, pp. 14- 
23 (1996)

6. Tanaka K., Ikeda T. and Wang H. O., " Robust stabilization of a class of uncertain nonlinear systems via fuzzy control: quadratic stabilizability, control theory, and linear matrix inequalities," IEEE Trans. Fuzzy Syst., Vol. 4, pp. 1-13 (1996).

7. Ma X. J., Sun Z. O. and He Y. Y., “Analysis and design of fuzzy controller and fuzzy observer," IEEE Trans. Fuzzy Syst., Vol. 6, pp. 41-51 (1998).

8. Clough R. W. and Penzien J., Dynamics of Structures, Mcgraw-Hill, New York.

9. Joo Y. H., Shieh L.S. and Chen G., "Hybrid state-space fuzzy model-based controller with dual-rate sampling for digital control of chaotic systems," IEEE Trans. Fuzzy Syst., Vol. 7, pp. 394-408 (2000).

10. Takagi T. and Sugeno M., "Fuzzy identification of systems and its applications to modeling and control," IEEE Trans. Syst., Man, Cybern., Vol. 15, pp. 116-132 (1985).

11. Lin W. and Byrnes C. I., " $H^{\infty}$-Control of Discrete-Time Nonlinear Systems," IEEE Trans. Automatic Control, Vol. 41, pp. 494-510 (1996).

12. Hwang C. N., "Formulation of $H_{2}$ and $H_{\infty}$ optimal control problems- A variational approach," Journal of The Chinese Institute of Engineering., Vol. 16, pp. 853866 (1993).

13. Zhou K. and Khargonedkar P. P., "Robust stabilizaion of linear systems with norm-bounded time-varying uncertainty," Sys. Control Lett., 10, pp. 17-20 (1988).

\section{PDC模糊控制器在具有外來千擾的 非線性系統之應用與強健 $H^{\infty}$ 控制}

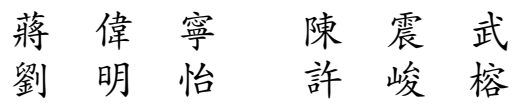

國立中央大學土木工程學系

$$
\text { 摘 要 }
$$

本文利用李雅普諾夫直接法(Lyapunov's direct method)推導一穞定準則。此穞定準則可確保非線性 系統達到穞定。經由定理證明, 吾人可由 LMI (Linear Matrix Inequality)最佳演算法求得正定矩陣 $\mathrm{P}$ 以確保定理滿足。文中提出平行分散補償(Parallel Distributed Compensation, PDC) 的控制技巧, 藉此 架構吾人將設計一模糊控制器以穞定非線性系統。文 末, 舉一共振與一混沌的例子, 藉由數值模擬證實理 論可行。 